\title{
Research of Method for Improving Antifreeze-Thaw Performance Based on Asphalt Mixture Freeze-Thaw Damage Development Process
}

\author{
Yazhen Sun, ${ }^{1}$ Man Deng, ${ }^{1}$ Youlin Ye, ${ }^{2}$ Lin Gao, ${ }^{3}$ Huaizhi Zhang $\mathbb{D}^{1},{ }^{1}$ and Zuoxin $\mathrm{Ma}^{4}$ \\ ${ }^{1}$ School of Transportation Engineering, Shenyang Jianzhu University, Shenyang 110168, China \\ ${ }^{2}$ School of Civil Engineering, Shenyang Jianzhu University, Shenyang 110168, China \\ ${ }^{3}$ College of Civil Engineering, Chongqing University of Arts and Sciences, Chongqing 402160, China \\ ${ }^{4}$ China Construction and Third Bureau First Engineering Co., Ltd., Wuhan 430040, China \\ Correspondence should be addressed to Huaizhi Zhang; huaizhi.zhang@163.com
}

Received 23 May 2020; Revised 9 August 2020; Accepted 18 August 2020; Published 27 August 2020

Academic Editor: Linglin Li

Copyright (C) 2020 Yazhen Sun et al. This is an open access article distributed under the Creative Commons Attribution License, which permits unrestricted use, distribution, and reproduction in any medium, provided the original work is properly cited.

To improve the antifreeze-thaw performance of asphalt pavement in the seasonal freezing regions, the temperature and the time of freeze-thaw test were redesigned based on the climatic characteristics of the regions, and the splitting tensile strength tests were carried out to determine the low-temperature performance of the asphalt mixture under the influence of the gradation and the asphalt-aggregate ratio. A mathematical model was built to investigate the freeze-thaw damage law. According to the test results of splitting tensile strength of the asphalt mixture under freeze-thaw cycles, the probabilistic damage variable of the asphalt mixture was redefined and a physical probability model was built to analyse the freeze-thaw damage. Based on the freeze-thaw damage development process and the mechanism of the asphalt mixture, the effective measures to improve the antifreeze-thaw performance were provided and demonstrated through the correlations among the damage parameters (the shape parameter $\alpha$, the scale factor $\lambda$, and the gradient factor $\nu$ ) and the freeze-thaw resistance of the asphalt mixture. The test results showed that the splitting tensile strength decreased with the increase of the number of the freeze-thaw cycles. With the same gradation, the splitting freeze-thaw damage degree of the asphalt mixture with $5.8 \%$ asphalt-aggregate ratio is about $6 \%$ less than others after the 18 th freeze-thaw cycle. The freeze-thaw resistance increases with the asphalt-aggregate ratio. With the same asphalt-aggregate ratio, the splitting freeze-thaw damage degree of S-grade mixtures is about $11.8 \%$ higher than that of Z-grade mixtures. S-grade mixtures have positive effects on the freeze-thaw resistance. The results suggest new measures for further investigation on the design and maintenance of the asphalt mixture in the seasonal freezing regions.

\section{Introduction}

Asphalt pavements are widely used in China's highway constructions due to the advantages, such as the high driving comfort and the low noise. An asphalt mixture is generally considered to be a complex porous material which includes the asphalt, the aggregates, and the fillers, as well as the large number of voids. The freeze-thaw damage of the asphalt pavement can be caused by low temperature and moisture, which is very unfavorable to the construction of highways in the seasonal freezing regions. The seasonal freezing regions spread over 10 provinces of China and distribute in large areas across the territory. The civil infrastructures are faced with the problems of damage and freeze-thaw resistance of the asphalt mixture, which are acknowledged the critical issues worldwide [1-3].

Researchers have studied the freeze-thaw damage development mechanism of the asphalt mixture and revealed the simultaneous effects of the water flow, the deicing salt and the calcium acetate on asphalt concrete deterioration under freeze-thaw cycles [4-7]. The results showed that the freeze-thaw cycles and the low temperature had obvious impact on the compressive properties of the mixture in cold plateau regions [8]. The durability of the concrete with fly 
ash as fine aggregate under the freeze-thaw cycles has been discussed, providing the theoretical reference and basis for the analysis of concrete durability in the multifactor environment [9]. With the development of technology, the test equipment has also been improved. The X-ray CT technique is widely employed to capture the internal structure of the asphalt mixtures. The damage mechanism of the asphalt mixture under freeze-thaw cycle has been obtained [10-13]. In the field of concrete research, the three-parameter Weibull distribution model has been employed to conduct the probabilistic damage analysis. The relationships between the service life and the damage parameter for different probabilities of reliability have been explicitly established, from which the service life of the concrete subjected to cyclic freezing and thawing actions has been determined at the given reliability index [14]. In order to extend the service life of the steel bridge deck pavement, an LLSBDP structure "EAC + SMA" has been proposed. The "EAC + SMA" structure can be used to extend the service life of the steel bridge deck pavement based on a numerical analysis [15]. Based on steering wheel difference angle through the Delphi method, an evaluation model has been established to investigate the influence of different rutting depths on driving [16].

In the research on the freeze-thaw resistance of the asphalt mixtures, the dynamic nondestructive test has been employed to evaluate the antifreeze-thaw performance of the asphalt mixtures. It was found that the rubber asphalt mixture had better antifreeze-thaw performance than the neat asphalt mixture; the particle size of rubber powder also showed an impact on the freeze-thaw performance of the asphalt mixture [17-19]. In recent years, it has been observed the polyester fiber content can exert an effect on the air voids and low-temperature performance [20]. Some studies have shown that the basalt fiber-diatomite-modified asphalt mixture had better low temperature crack resistance and antifreeze-thaw cycle capacity compared to the control asphalt mixture [21, 22].

Based on the research results, efforts have been made to assess the frost-induced internal damage of the asphalt mixture using both freeze-thaw cycle and damage. In order to improve the freeze-thaw resistance of the asphalt mixtures, most research studies have considered the improving of material properties. However, few studies suggested methods to improve the antifreeze-thaw performance, which were influenced by the character of the mixture, such as the gradation, the asphalt-aggregate ratio, and the specific damage-development paths. Therefore, this study redefined the damage degree of the asphalt mixture using the test results of splitting tensile strength of the asphalt mixture under freeze-thaw cycles. The first-order differential damage evolution equation was obtained by introducing the difference method. Weibull distribution model was employed to conduct the probabilistic damage analysis and the development characteristics analysis of the freeze-thaw damage which was affected by the gradation and the asphaltaggregate ratio. The effective methods to improve antifreezethaw performance for different types of asphalt mixtures were provided and demonstrated through the freeze-thaw damage process. This paper can be used as a reference for further investigation on the design and maintenance of the asphalt mixture in seasonal freezing regions.

\section{Materials and Methods}

2.1. Materials. In this study, Liaohe-90\# matrix heavy traffic asphalt is used as the binder. The specifications are listed in Table 1.

Both the aggregate and the mineral powder are limestone. The specifications are given in Tables 2 and 3.

In order to investigate the effect of gradations on freezethaw damage of materials, two aggregate gradations (AC$13 \mathrm{~S}$ and AC-13Z) were designed based on T0702-2011 specified in JTG E20-2011. The gradations are listed in Table 4 and the gradation curves are shown in Figure 1. According to the Marshall design procedure, the optimum asphalt content (OAC) of the two types of asphalt mixtures is $5.3 \%$. To investigate the influence of the asphalt-aggregate ratio on the antifreeze-thaw performance of the asphalt mixture, asphalt mixtures of three types with asphalt-aggregate ratios differing from the $\mathrm{OAC}$ by $\pm 0.5 \%$, i.e., $4.8 \%$, $5.3 \%$, and $5.8 \%$, respectively, were selected for the research.

2.2. Test Method. With the asphalt-aggregate ratios and the gradations mentioned above, six Marshall specimens were made by gyratory compaction method according to the Chinese specification of JTG E20-2011. The specimens were compacted in a Marshall Compactor with 50 beats on each side.

According to JTG E20-2011, every specimen was immersed in water and a vacuum of $97.3 \sim 98.7 \mathrm{kPa}$ $(730 \sim 740 \mathrm{Hg})$ for $15 \mathrm{~min}$ and soaked in atmospheric pressure for $30 \mathrm{~min}$. Each cycle consisted of freezing at $18 \pm 2^{\circ} \mathrm{C}$ for $16 \pm 1 \mathrm{~h}$, followed by soaking in water at $60 \pm 0.5^{\circ} \mathrm{C}$ for $24 \mathrm{~h}$. Before freezing, the specimen was placed into a plastic bag with $10 \mathrm{ml}$ water. Before thawing, the specimen was removed from the plastic bag. The actual conditions in the seasonal freezing regions of northern China have been taken into account. For example, the average minimum temperature in winter in Shenyang is $-18^{\circ} \mathrm{C}$, and the average maximum temperature in summer is $35^{\circ} \mathrm{C}$. Taking the most unfavorable state into account, the new temperature and the time of the freeze-thaw cycle were redefined. Each cycle consisted of freezing at $-20^{\circ} \mathrm{C}$ for $8 \mathrm{~h}$, followed by soaking in water at $36.8^{\circ} \mathrm{C}$ for $8 \mathrm{~h}$. After $0,2,4,6,8,10,14$, and 18 freezethaw cycles, the splitting tensile strength test was carried out, which is shown in Figure 2. The specimen was placed in a $25^{\circ} \mathrm{C}$ dry condition room for $2 \mathrm{~h}$ before the splitting tensile strength test. Based on JTG E20-2011, the specimen after the freeze-thaw cycle was tested at the temperature of $-10^{\circ} \mathrm{C}$ and the constant loading rate was $20 \mathrm{~mm} / \mathrm{min}$. During the test, the height of the specimen and the failure load were recorded by computer and the splitting tensile strength was calculated.

2.3. Results and Discussion. Figure 3 shows that the splitting tensile strength $\left(R_{\mathrm{T} n}\right)$ of all types of asphalt mixtures decreases with the increase of the number of freeze-thaw 
TABle 1: Technical index of Liaohe-90 \# matrix heavy traffic asphalt.

\begin{tabular}{|c|c|c|c|}
\hline Test item & Unit & Measurement & Technical criterion \\
\hline Penetration $\left(25^{\circ} \mathrm{C}, 100 \mathrm{~g}, 5 \mathrm{~s}\right)$ & $0.1 \mathrm{~mm}$ & 84 & $80 \sim 100$ \\
\hline Ductility $\left(5 \mathrm{~cm} / \mathrm{min}, 15^{\circ} \mathrm{C}\right)$ & $\mathrm{cm}$ & $>140$ & $\geq 100$ \\
\hline Softening point & ${ }^{\circ} \mathrm{C}$ & 48.5 & $42 \sim 52$ \\
\hline Flash point & ${ }^{\circ} \mathrm{C}$ & 280 & $>245$ \\
\hline Wax content (distillation) & $\%$ & 1.6 & 2.2 \\
\hline Density $\left(15^{\circ} \mathrm{C}\right)$ & $\mathrm{g} / \mathrm{cm}^{3}$ & 1.033 & - \\
\hline Solubility (trichloroethylene) & $\%$ & 99.5 & 99.5 \\
\hline Mass loss & $\%$ & 0.5 & \pm 0.8 \\
\hline Penetration ratio & $\%$ & 68 & $\geq 57$ \\
\hline
\end{tabular}

TABLE 2: Apparent density and water absorption of aggregate.

\begin{tabular}{lccccccccc}
\hline Sieve size $(\mathrm{mm})$ & 13.2 & 9.5 & 4.75 & 2.36 & 1.18 & 0.6 & 0.3 & 0.15 & 0.075 \\
\hline Apparent density $\left(\mathrm{g} / \mathrm{cm}^{3}\right)$ & 2.788 & 2.760 & 2.70 & 2.658 & 2.652 & 2.636 & 2.614 & 2.602 & 2.588 \\
Water absorption $(\%)$ & 0.79 & 0.95 & 1.19 & - & - & - & - & - & - \\
\hline
\end{tabular}

TABLE 3: Test results of limestone mineral powder performance.

\begin{tabular}{llcc}
\hline Test item & & Measurement & Technical criterion \\
\hline \multirow{2}{*}{ Sieving test $(\%)$} & $<0.6 \mathrm{~mm}$ & 100 & 100 \\
& $<0.15 \mathrm{~mm}$ & 93.2 & $90 \sim 100$ \\
& $<0.075 \mathrm{~mm}$ & 84.0 & $75 \sim 100$ \\
Hydrophilic coefficient & & 0.76 & $<1$ \\
Apparent density $\left(\mathrm{g} / \mathrm{cm}^{3}\right)$ & & 2.72 & $>2.50$ \\
\hline
\end{tabular}

TABLE 4: Gradations.

\begin{tabular}{lcccccccccc}
\hline Sieve size & 16 & 13.2 & 9.5 & 4.75 & 2.36 & 1.18 & 0.6 & 0.3 & 0.15 & 0.075 \\
\hline Upper limit (\%) & 100 & 100 & 85 & 68 & 50 & 38 & 28 & 20 & 15 & 8 \\
AC-13Z (\%) & 100 & 95 & 76 & 53 & 37 & 29 & 19 & 13 & 10 & 6 \\
AC-13S (\%) & 100 & 96 & 76 & 42 & 28 & 21 & 14 & 11 & 9 \\
Lower limit (\%) & 100 & 90 & 68 & 38 & 24 & 15 & 10 & 7 & 5 \\
\hline
\end{tabular}

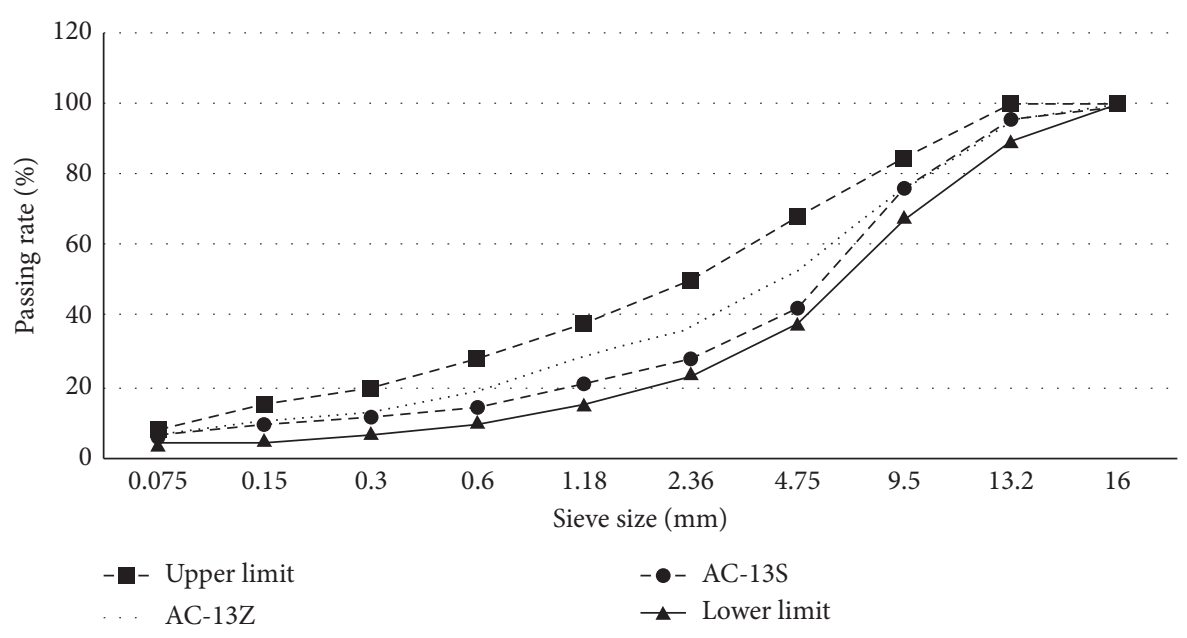

Figure 1: Gradation curves.

cycles. However, the splitting strength of different types of asphalt mixtures presents different trends with the freeze-thaw cycles. $R_{\mathrm{T} n}$ decreases significantly in the first
4 freeze-thaw cycles and decreases to a lower level after the 10th freeze-thaw cycle. After the 14th freeze-thaw cycle, the decrease slowed down obviously. 


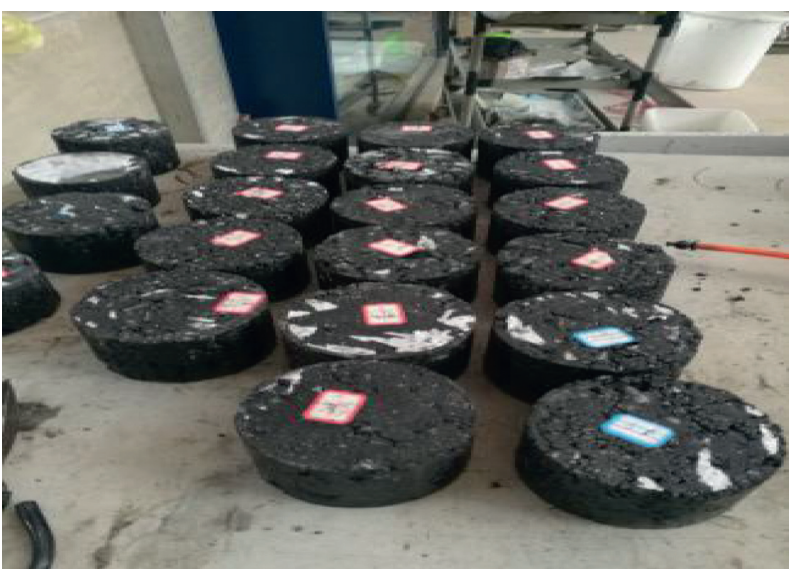

(a)

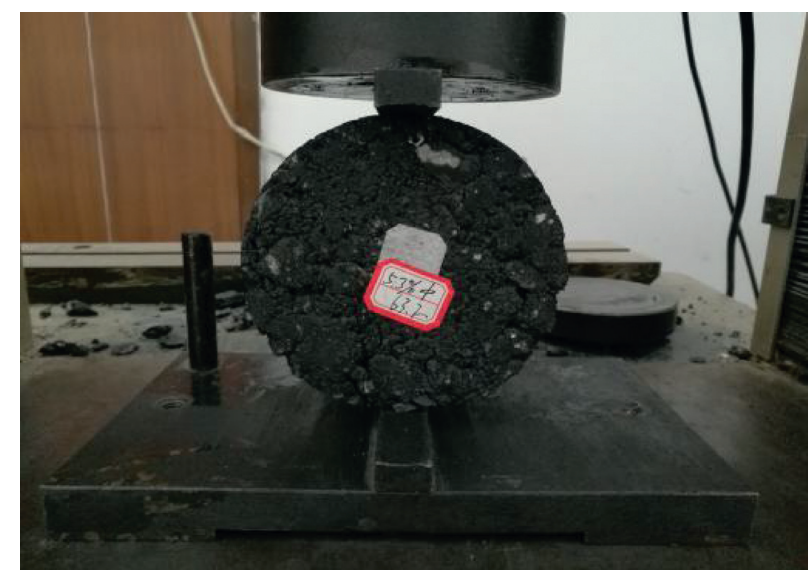

(b)

Figure 2: Freeze-thaw splitting test. (a) Small Marshall specimens. (b) Splitting test.

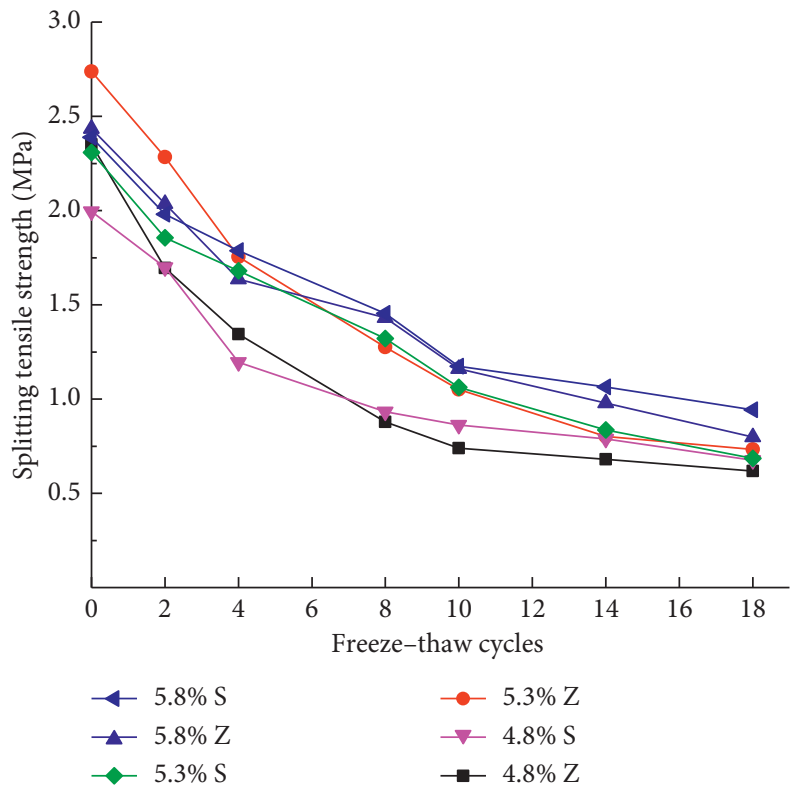

Figure 3: Curves of splitting tensile strength versus freeze-thaw cycle.

It is well accepted that the strength loss of the asphalt mixture exposed to the freeze-thaw cycle is caused by the expansion of freezing water in the void system, the osmotic pressure of the mixture during the freezing process and the decrease of the cohesion of the mixture. Here are the interpretations for the attenuation of the splitting tensile strength of the mixtures after the freeze-thaw cycle.

The strength rapidly decreases in the first 4 freeze-thaw cycles, which is due to the frost-heave force caused by the volume expansion and temperature stress. The internal structure of the asphalt mixtures is damaged and the internal microcracks accumulate and grow quickly in the paste and the aggregate of the asphalt mixture during the freezing and thawing, which affects the stability of the skeleton structure of the mixture, so the strength reduces faster. After the 4 th freeze-thaw cycle, the splitting strength of the mixture is further reduced and the internal microcracks are further diffused to form interconnected pores. The frost-heave force is dissipated to a certain extent. After the 10th freeze-thaw cycle, the splitting strength of the mixture decreases slowly. The void ratio increases and the frost-heave force tends to be stable with the increase of the number of freeze-thaw cycle.

\section{Study on Freeze-Thaw Damage Characteristics of Asphalt Mixtures}

3.1. Attenuation Law of Asphalt Mixture on Freeze-Thaw Damage. The splitting tensile strength test is effective in the evaluating of asphalt mixture degradation through the freeze-thaw cycles. Therefore, the damage degree of asphalt mixture due to freezing and thawing is defined as 


$$
D_{\mathrm{T} n}=1-\frac{R_{\mathrm{T} n}}{R_{\mathrm{T} 0}},
$$

where $D_{\mathrm{T} n}$ is the damage degree of the asphalt mixture at the $n$th freeze-thaw cycle, $R_{\mathrm{T} n}$ is the splitting tensile strength of damaged samples at the $n$th freeze-thaw cycle, and $R_{\mathrm{T} 0}$ is the splitting tensile strength of intact (unconditioned) samples, respectively.

By analyzing the change of damage degree with the number of freeze-thaw cycles, the relationship between the damage degree and the freeze-thaw cycles can be obtained. It is observed that the curves of the damage degree of asphalt mixture $D_{\mathrm{T} n}$ are nonlinear, and the variation trends can be fitted in the exponential function form, as shown in Figures 4 and 5. All correlation coefficients $R$ are larger than 0.9 , as shown in Table 5 . Therefore, the equation that simulates the variation of the damage degree of the asphalt mixture $D_{\mathrm{T} n}$ as the freezethaw cycles changes is written as

$$
D_{\mathrm{T} n}=1-e^{-a n},
$$

where $a$ is a parameter relating to the antifreeze-thaw performance. The larger the value, the higher the position of the curve line is, which indicates that the damage of the mixture is large and the freeze-thaw resistance is weak. The values of parameter $a$ for different types of mixtures are shown in Figures 4 and 5.

Figures 4 and 5 illustrate the relationships between the number of freeze-thaw cycles and the damage degree of the asphalt mixture. It can be seen from the figures that the damage degrees of all types of the asphalt mixtures are on a stable increase with the number of freeze-thaw cycles. For $\mathrm{Z}$-grade mixture, the splitting-freeze-thaw damage degree of the $5.8 \%$-asphalt-aggregate-ratio mixture is $67.19 \%$ after the 18 th freeze-thaw cycle, which is $6.55 \%$ and $6.05 \%$ lower than the other two types of mixtures, respectively. For S-grade mixture, the splitting-freeze-thaw damage degree of the $5.8 \%$-asphalt-aggregate-ratio mixture is $60.53 \%$ after the 18th freeze-thaw cycle, which is $5.58 \%$ and $9.8 \%$ lower than the other two types of mixtures, respectively. Ordinarily, a smaller damage degree value means a preferable antifreezethaw property, indicating that the increasing asphalt-aggregate ratio has a significant influence on the antifreezethaw property of the asphalt mixture. For the mixture with the same asphalt-aggregate ratio, the damage degree of $\mathrm{S}$-grade mixture is lower than that of Z-grade, and the maximum difference is $11.8 \%$, which indicates that $S$-grade mixture has better antifreeze-thaw property than Z-grade mixture. It is observed in Figures 4 and 5 that the value $a$ of the $5.8 \%$-asphalt-aggregate-ratio mixture is always the minimum, indicating that its antifreeze-thaw property is the best with the two mixtures (Z-grade and S-grade). The value $a$ of S-grade mixture is smaller than that of Z-grade mixture, which indicates that S-grade mixture has better freeze-thaw resistance.

3.2. Damage Evolution of Asphalt Mixture. To study the freeze-thaw damage evolution process of the six types of asphalt mixtures, the first order difference of the damage degree at the $n$th freeze-thaw cycle is calculated, and the damage evolution equation is obtained as

$$
\Delta D_{\mathrm{T} n}=D_{\mathrm{T} n+1}-D_{\mathrm{T} n}=1-e^{-a(n+1)}-\left(1-e^{-a n}\right)=\left(1-e^{-a}\right) e^{-a n} .
$$

The splitting-freeze-thaw damage evolution curves are plotted in Figure 6. The line position of the curve represents the damage evolution rate. The higher the line position, the faster the damage evolution rate is and the faster the damage degree decreases. The splitting-freeze-thaw damage evolution curves show that the splitting freeze-thaw damage evolution process of Z-grade and S-grade asphalt mixtures is divided into three stages: the rapid damage stage, the stable damage stage, and the developing damage stage. In the first stage, the bound water in the pores of the asphalt mixtures produces a periodic phase change and microcracks emerge near the interface between the asphalt and the aggregate on the surface of the asphalt mixtures so that the water continuously infiltrates during the freezing process. The damage increases rapidly, and the mechanical properties are significantly reduced. However, for the $4.8 \%$ asphalt-aggregate ratio mixture, the rapid damage stage is during the $0-8$ freeze-thaw cycles. This is because this type of mixture has a large initial void fraction and is greatly affected by the frost-heave force. In the second stage, the internal structure tends to be in a stable state. Meanwhile, the expanded and connected voids have a certain dissipation effect on the frost-heave force of ice. The rate of damage evolution decreases. In the last stage, the frostheave force continues to work, and the microcracks develop further, causing severe damage to the mixture until damage occurs.

\section{Probabilistic Damage Modeling under Freeze-Thaw Action and Statistical Damage Evolution Analysis}

4.1. Theoretical Background of the Damage Model for Asphalt Mixture Subjected to Frost [23-28]. Based on the research result [29], the universal damage model of concrete was used to account for different failure mechanisms under the freeze-thaw condition. This damage evolution method has been gradually introduced into the asphalt concrete from the field of cement concrete, and it is reasonable and feasible to apply it to the freeze-thaw damage evolution analysis of the asphalt mixtures. Monotonic compressive strength tests were designed to build a crack evolution model by pseudo-J-integral Paris' law [30]. The crack propagation model based on pseudo-J-integral Paris' law was able to accurately characterize the crack propagation in bituminous binders under a rotational shear fatigue load [31]. And crack length- (CL-) based healing index was a fundamental and accurate parameter to evaluate the healing rate and healing potential of the bitumen [32]. This study aims to develop a damage model for asphalt mixture subjected to freeze-thaw action with damage theory and physical probability theory. 


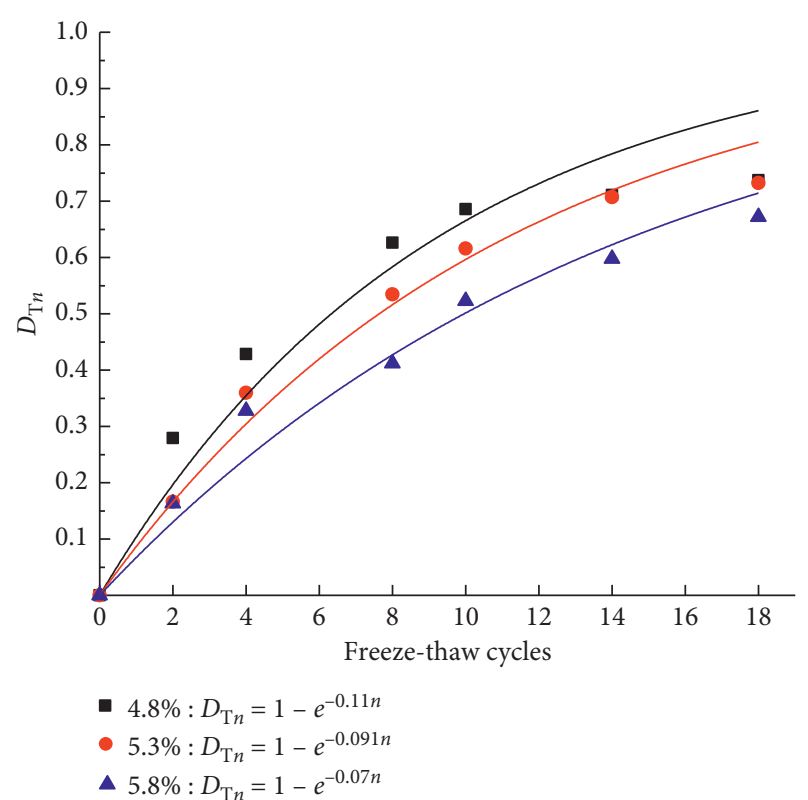

FIGURE 4: Fitting curves of split degree of freeze-thaw damage vs. freeze-thaw cycle of Z-grade mixtures.

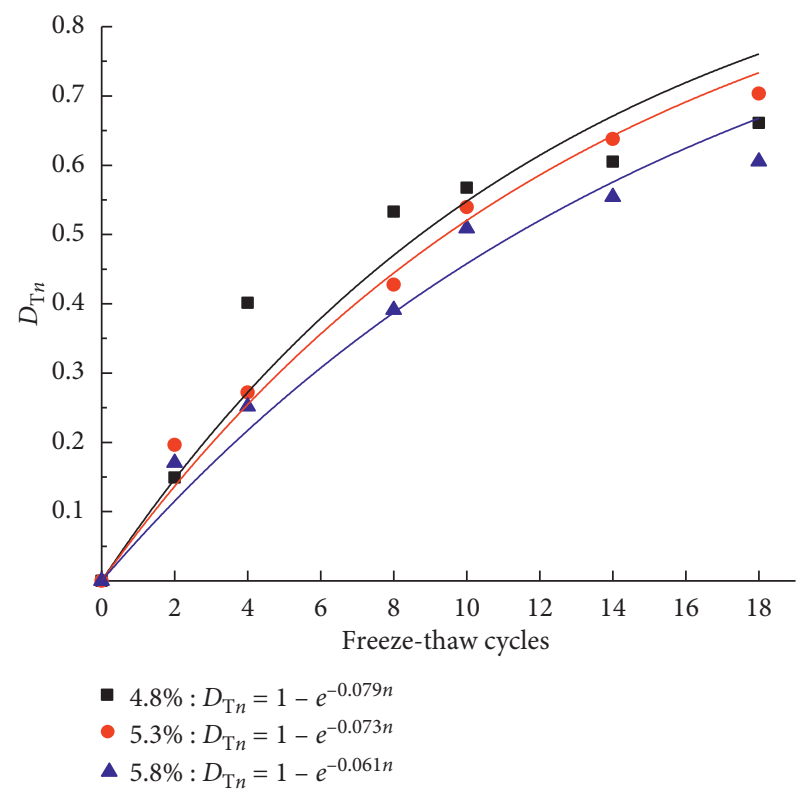

Figure 5: Fitting curves of the split degree of freeze-thaw damage vs. freeze-thaw cycle of S-grade mixtures.

TABle 5: Correlation coefficients $R$.

\begin{tabular}{lcccccc}
\hline Type & $4.8 \% \mathrm{Z}$ & $5.3 \% \mathrm{Z}$ & $5.8 \% \mathrm{Z}$ & $4.8 \% \mathrm{~S}$ & $5.3 \% \mathrm{~S}$ & $5.8 \% \mathrm{~S}$ \\
\hline$R$ & 0.92295 & 0.98064 & 0.96716 & 0.90664 & 0.98598 & 0.96227
\end{tabular}

4.1.1. Model Concept and Hypotheses. Figure 7 represents the 3D model of a structural asphalt mixture element with a square cross-section. The small, solid block inside the square represents a microelement of the asphalt mixture. The hypotheses are as follows.
Hypothesis 1. The asphalt mixture is isotropic and homogeneous.

Hypothesis 2. For simplicity, it is assumed that all of the microelements with the same minimum distance to the boundary of the domain have the same damage evolution.

Hypothesis 3. The damages of the microelements are assumed to be independent random variables following the three-parameter Weibull distribution. The probability density function (PDF) for the three-parameter Weibull distribution is defined as

$$
F(t)=1-\exp \left[-(\lambda t)^{\alpha}\right],
$$

where $t$ is the time, $\alpha$ is the shape parameter, and $\lambda$ is the scale factor.

Hypothesis 4. The shape parameter $\alpha$ can be regarded as a constant because the shape of the probability distribution function of the damage of the asphalt mixture at all locations should be similar if the microelements is adversely affected by the same type of damage.

4.1.2. Probabilistic Damage Evolution Model. Based on Hypothesis $2, \lambda$ has the form

$$
\lambda(x, y, z)=\lambda(|x|,|y|,|z|) .
$$

Take a microelement at the position $(x, y, z) . f(x, y, z ; t)$ is the probability density function of the damage of the microelement at the position $(x, y, z)$. The random variable $Q$ $(x, y, z ; t)$ is the damage volume of the microelement at time $t$, and $Q(x, y, z ; t)$ follows the Poisson distribution. The damage probability $P$ at time $t$ is

$$
P=f(x, y, z, t) \mathrm{d} \zeta \mathrm{d} \eta \mathrm{d} \gamma .
$$

Based on the expected properties of Poisson distribution, the expected value of the random variable $Q(x, y, z ; t)$ is

$$
\begin{aligned}
E(Q) & =n p=\mathrm{d} x \mathrm{~d} y \mathrm{~d} z \mathrm{~d} \gamma^{-1} \mathrm{~d} \zeta^{-1} \mathrm{~d} \eta^{-1} f(x, y, z, t) \mathrm{d} \zeta \mathrm{d} \eta \mathrm{d} \gamma \\
& =f(x, y, z, t) \mathrm{d} x \mathrm{~d} y \mathrm{~d} z,
\end{aligned}
$$

where $n$ is the number of sample points in the entire domain. The failed volume of the mixture is

$$
V=\int_{V_{0}} E(Q) \text {. }
$$

The probabilistic damage variable of asphalt mixture $D_{\mathrm{V}}$ is defined as the ratio of the failed volume to the total volume:

$$
D_{\mathrm{V}}=\frac{\Delta V}{V_{0}}=1-\frac{V}{V_{0}},
$$

where $\Delta V$ is the failed volume, $V$ is the undamaged volume, and $V_{0}$ is the total volume.

Combining equations (7)-(9), the freeze-thaw damage evolution equation is obtained: 


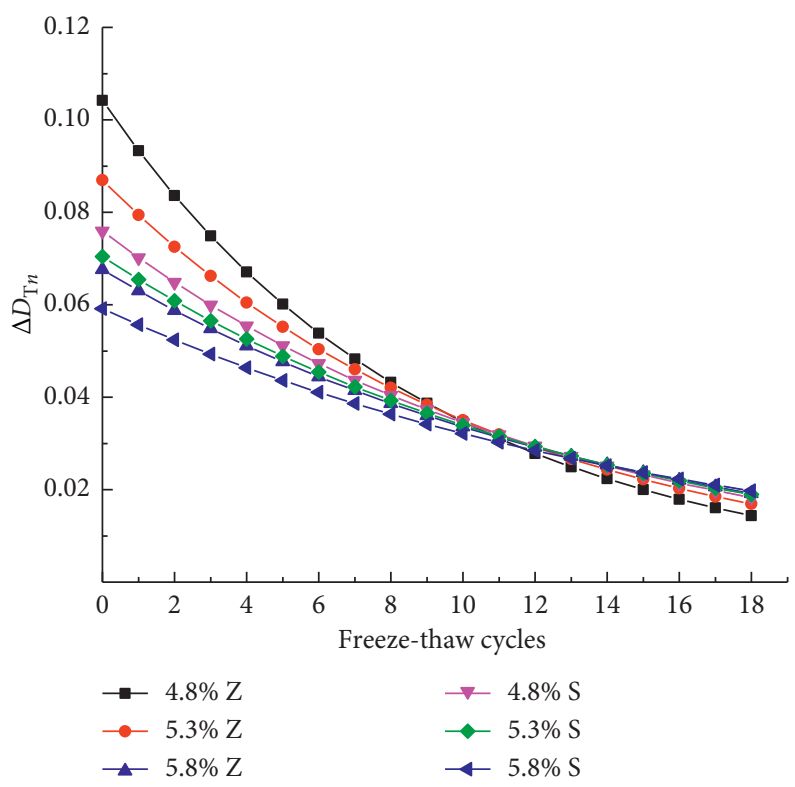

FIgURE 6: Evolution curves of split freeze-thaw damage.

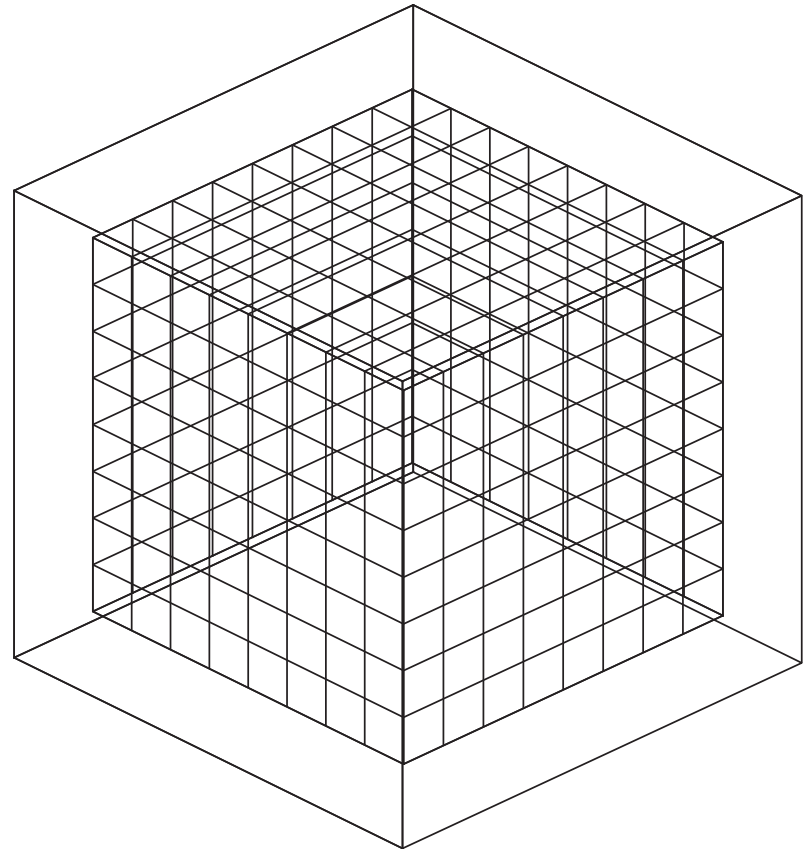

FIGURe 7: Physical probability model of damage degree for asphalt mixtures subjected to freezing and thawing.

$$
\begin{aligned}
D_{\mathrm{V}} & =V_{0}^{-1} \int_{V_{0}} f(x, y, y, t) \mathrm{d} x \mathrm{~d} y \mathrm{~d} z \\
& =V_{0}^{-1} \int_{V_{0}} \alpha[\lambda(|x|,|y|,|z|) t]^{\alpha-1} \exp \left[-(\lambda t)^{\alpha}\right] \mathrm{d} x \mathrm{~d} y \mathrm{~d} z .
\end{aligned}
$$

4.1.3. Numerical Approximation. As shown in Figure 7, the domain is discretized into $N$ ( $N$ is an even number) equally spaced microelements. Based on Hypothesis 2, the number of the microelements with the same minimum distance to the boundary of the domain is

$$
N_{i}=6 N^{2}-24 i N+24 i^{2}-12 N+24 i+8,
$$

where $i=1,2, \ldots,(N / 2-1)$ and $F_{i}(t)$ is the cumulative density function (CDF), which is regarded as the probability of failure.

Based on Hypothesis 3, according to probability theory and mathematical statistics, when the total number of sample points is small, the Poisson distribution and Bernoulli distribution can be considered to be the same. At time $t$, the freeze-thaw damage event of the $n_{\mathrm{i}}$ block of the unit $\Phi_{i}$ follows the Bernoulli distribution. The expected value is

$$
E\left(\phi_{i}\right)=N_{i} F_{i}(t) .
$$

According to Hypothesis 4,

$$
F_{i}(t)=1-\exp \left[1-\left(\lambda_{i} t\right)^{\alpha}\right] .
$$

Therefore, the mathematical expectation of the total microelements destruction at time $t$ is

$$
E(\omega)=\sum_{i=0}^{(N / 2)-1} E\left(\phi_{i}\right)=\sum_{i=0}^{(N / 2)-1} N_{i} F_{i}(t) .
$$

The expected value of freeze-thaw damage is

$$
\begin{aligned}
E\left(D_{\mathrm{V}}\right)= & N^{-3} \sum_{i=0}^{(N / 2)-1}\left(6 N^{2}-24 i N+24 i^{2}-12 N+24 i+8\right) \\
& \cdot\left\{1-\exp \left[-\left(\lambda_{i} n\right)^{\alpha}\right]\right\},
\end{aligned}
$$

where $N$ is the number of equal parts on each side of the model and is taken as an even number; $i=1,2, \ldots,(N / 2-1), n$ is the 
number of freeze-thaw cycles (take $0 / 2 / 4 / 8 / 10 / 14 / 18$ ), $\alpha$ is the shape parameter, and $\lambda$ is the scale factor, respectively.

According to the freeze-thaw damage model, the freezethaw damage process of AC-13 mixture is considered a cumulative process of its internal failure microelements, so the splitting freeze-thaw damage degree $D_{\mathrm{T} n}$ can be considered as the partial failure. The cumulative volume, combined with the above analysis, can be considered as $E$ $\left(D_{\mathrm{V}}\right)=E\left(D_{\mathrm{T} n}\right)$.

4.2. Research on Damage Development Process Based on Physical Probability Model. The shape Parameter $\alpha$ represents the Weibull shape parameter used to describe the change shapes of the curves. It reflects the differences in the evolution of freeze-thaw damage of different types of mixtures. The scale factor $\lambda$ reflects the magnitude of the resistance of the asphalt mixture to adverse conditions and is negatively related to the resistance of the material. The gradient factor $v$ reflects the differences in the evolution of freeze-thaw damage at different locations inside the asphalt mixture, and its absolute value is positively correlated with the magnitude of the difference. The value of $v$ is positive, and the damage of the asphalt mixture is propagated from the outside to the inside.

Some studies have made certain assumptions about the relationship between the scale factor and the gradient factor to investigate the internal damage process of the mixture under the freeze-thaw cycle. However, in fact, the relationship between the scale factor and the gradient factor is affected by the change in void ratio and the distribution of the voids. The damage process is uneven. Therefore, using the relationship between the expected value of freeze-thaw damage and the number of freezethaw cycles, the nonlinear relationship between the scale factor and the gradient factor was deduced to describe the freeze-thaw damage path of the asphalt mixture, and the development process of freeze-thaw damage of asphalt mixture can be described more accurately.

A 10-point grid freeze-thaw damage model was used for calculation. In a damage model that does not assume a linear relationship between the scale factor and the number of model layers, the scale factor $\lambda_{\mathrm{i}}$ of each layer continuously changes with the layer number $i$. The slope of the $\lambda_{i}-i$ curve can be regarded as the value of the gradient factor $\nu_{i}$. The fittings were performed using 1st OP software. The damage parameters obtained by the fittings are shown in Table 6. The model obtained is

$$
\begin{aligned}
E(D)= & 1-0.488 \exp \left[-\left(\lambda_{0} n\right)^{\alpha}\right]-0.296 \exp \left[-\left(\lambda_{1} n\right)^{\alpha}\right]-0.152 \\
& \cdot \exp \left[-\left(\lambda_{2} n\right)^{\alpha}\right]-0.056 \exp \left[-\left(\lambda_{3} n\right)^{\alpha}\right]-0.008 \exp \left[-\left(\lambda_{4} n\right)^{\alpha}\right] .
\end{aligned}
$$

Because the model does not make any assumptions about the relationship between the scale factor and the number of layers in the model, it can study the process of uneven damage of the asphalt mixture more specifically. Figure 8 shows the $\lambda_{0}-i-v$ relationships of different mixtures in this model.
It can be seen from Figure 8 that the asphalt-aggregate ratio and the gradation affect the freeze-thaw damage process of AC-13 asphalt mixture. It is observed in Figures 8 (a) and 8 (b) that there is a certain similarity between the two damage processes of Z-grade mixture of 5.8\% asphalt-aggregate ratio and S-grade mixture of $5.3 \%$ ratio. The scale factor goes up first, then goes down, and finally goes up. Synchronous damage advances slowly. It is observed in Figures 8(c) and 8(d) that there are some similarities between the two damage processes of Z-grade mixture of $5.3 \%$ ratio and S-grade mixture of $5.8 \%$ ratio, and the scale factor both increases to the maximum and then decreases and remains stable, indicating that the external resistance to freeze-thaw damage is better than the internal resistance to freeze-thaw damage, but the internal damage is more uniform, and the synchronous damage advances faster. It is observed in Figures 8(e) and 8(f) that the damage processes of the two gradation types of $4.8 \%$ ratio is different from other mixtures. For the Z-grade mixture of $4.8 \%$ ratio, the scale factor first stabilizes, then increases to the maximum with the number of layers $i$, and finally decreases, indicating that the external freeze-thaw resistance of this type of mixture is relatively low, and the damage develops from the outside to the inside. For S-grade mixture of $4.8 \%$ ratio, the scale factor first increases with the number of layers $i$, then stabilizes, then gradually increases, and then decreases, indicating that the type of mixture has poor freezethaw resistance and the damage develops from the middle of the inside to the outside.

To explain the freeze-thaw damage process based on different mixtures with splitting properties, a 3D model cross-section/longitudinal section diagram is used to describe the internal damage development path and severe damage area (indicated by the shaded regions), as shown in Figures 9(a)-9(f).

As shown in Figure 9(a), because the initial void ratio of Z-grade mixture of $4.8 \%$ asphalt-aggregate ratio is large, ice melts into water and penetrates into the interior of the asphalt mixture. The mixture is affected by the scouring and the frost-heave force, so the damage evolution of the mixture is from the outside to the middle, and the middle damage is the most serious. Therefore, appropriately improving the quantity of coarse aggregate and fine aggregate can improve antifreeze-thaw performance. In Figure 9(b), the OAC for Z-grade asphalt mixture is $5.3 \%$. The adhesion between asphalt and aggregate is good, but different distributing conditions of air voids and adhesion within the asphalt mixture lead to a slower advance rate of synchronous damage. Therefore, properly improving the quantity of medium and fine aggregates can improve antifreeze-thaw performance. As shown in Figure 9(c), as Z-grade mixture has higher asphalt content, most of the aggregates are in suspension. During the freeze-thaw process, the internal frost-heave force is uneven, and its internal damage is relatively serious. Therefore, appropriately reducing the amount of asphalt can improve the antifreeze-thaw performance. In Figure 9(d), due to the low asphalt content, S-grade mixture of $4.8 \%$ asphalt-aggregate ratio fails to form a dense structure inside the structure, and its severely 
TABLE 6: Damage parameters in process of uneven freeze-thaw damage.

\begin{tabular}{lcccccc}
\hline Type & $\alpha$ & $\lambda_{0}$ & $\lambda_{1}$ & $\lambda_{2}$ & $\lambda_{3}$ & $\lambda_{4}$ \\
\hline $4.8 \% \mathrm{Z}$ & 0.61435 & 0.10812 & 0.11274 & 0.11274 & 0.12183 & $4.18 E-16$ \\
$5.3 \% \mathrm{Z}$ & 1.27377 & 0.03972 & 0.2214 & 0.22947 & 0.23172 & 0.23172 \\
$5.8 \% \mathrm{Z}$ & 0.81153 & 0.04793 & 0.11728 & 0.0509 & 0.04906 & 0.61955 \\
$4.8 \% \mathrm{~S}$ & 1.13378 & 0.03474 & 0.28422 & 0.33227 & 0.33317 & 0.13446 \\
$5.3 \% \mathrm{~S}$ & 0.85453 & 0.07014 & 0.07027 & 0.07022 & 0.0702 & 0.24524 \\
$5.8 \% \mathrm{~S}$ & 0.92453 & 0.01922 & 0.13623 & 0.13629 & 0.13627 & 0.18316 \\
\hline
\end{tabular}

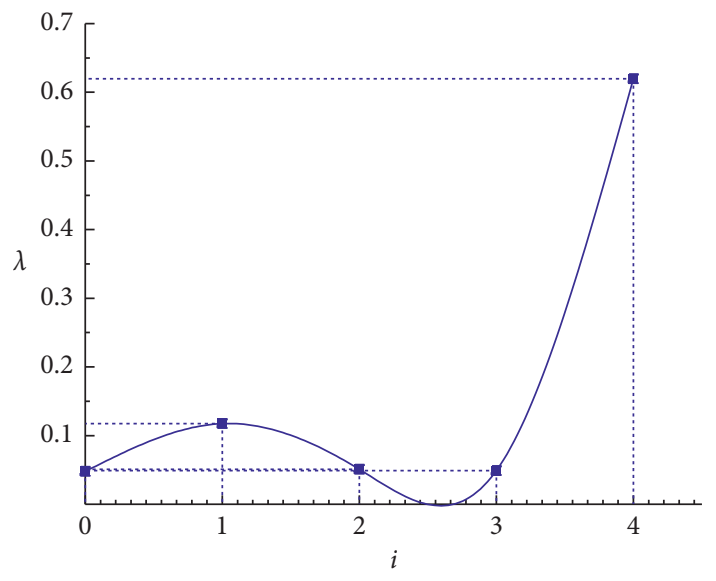

(a)

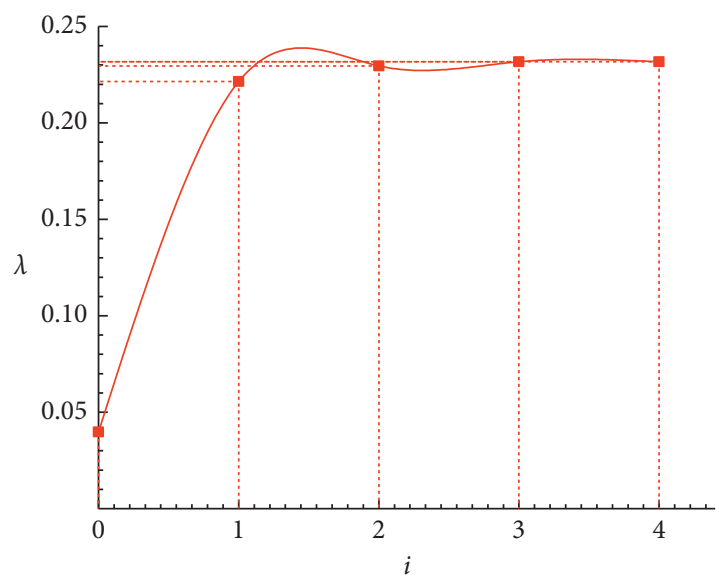

(c)

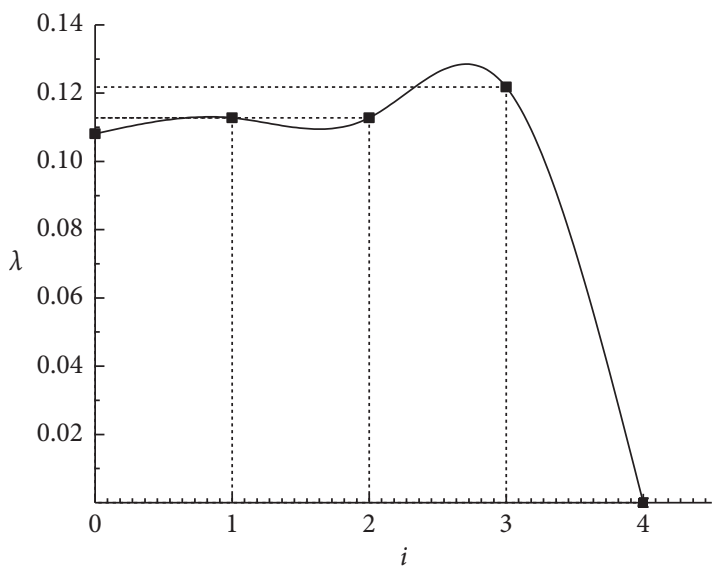

(e)

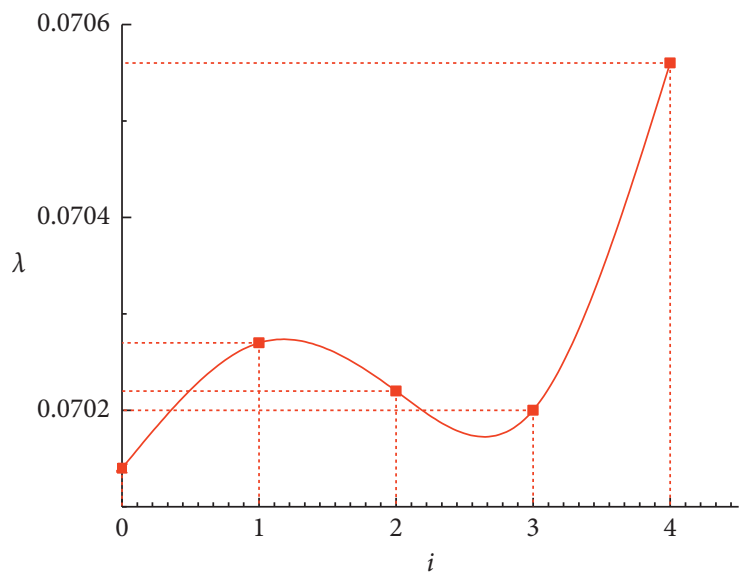

(b)

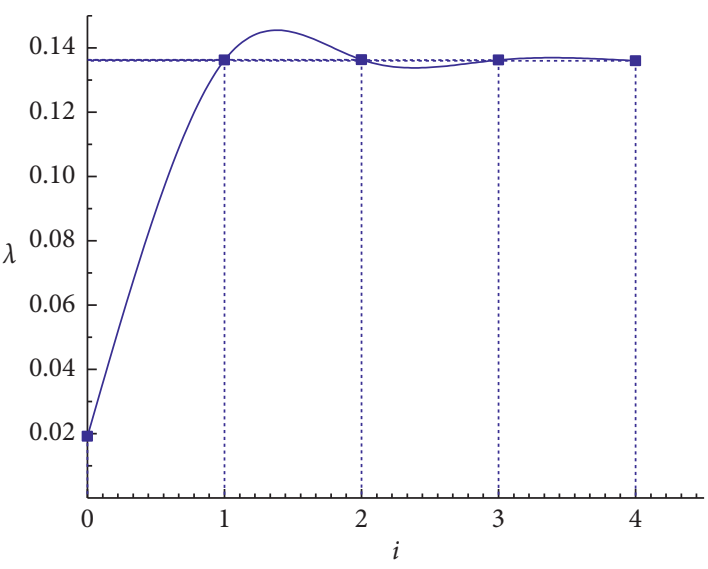

(d)

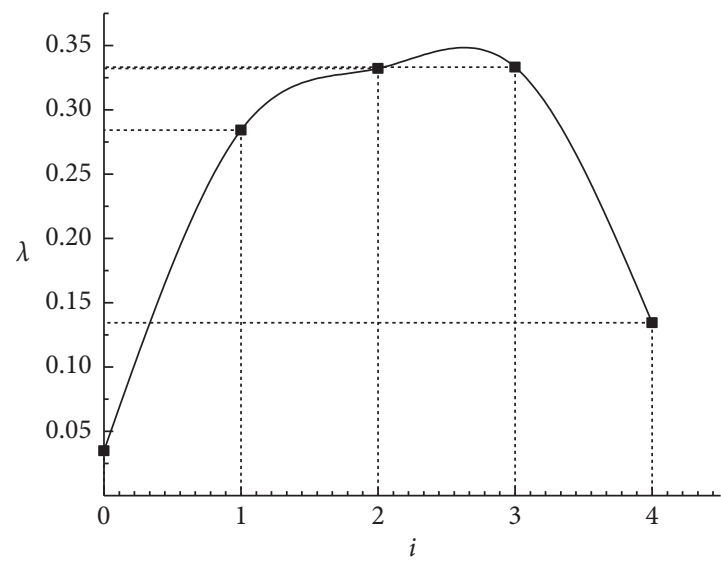

(f)

FIGURE 8: Relationships between different layers and scale factors by the model. (a) Z-grade of 5.8\% asphalt-aggregate ratio. (b) S-grade of $5.3 \%$ asphalt-aggregate ratio. (c) Z-grade of 5.3\% asphalt-aggregate ratio. (d) S-grade of 5.8\% asphalt-aggregate ratio. (e) Z-grade of 4.8\% asphalt-aggregate ratio. (f) $\mathrm{S}$-grade of $4.8 \%$ asphalt-aggregate ratio. 


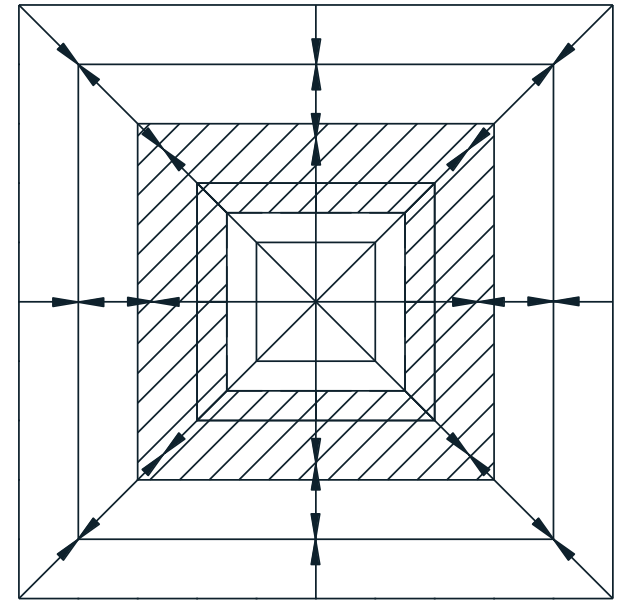

(a)

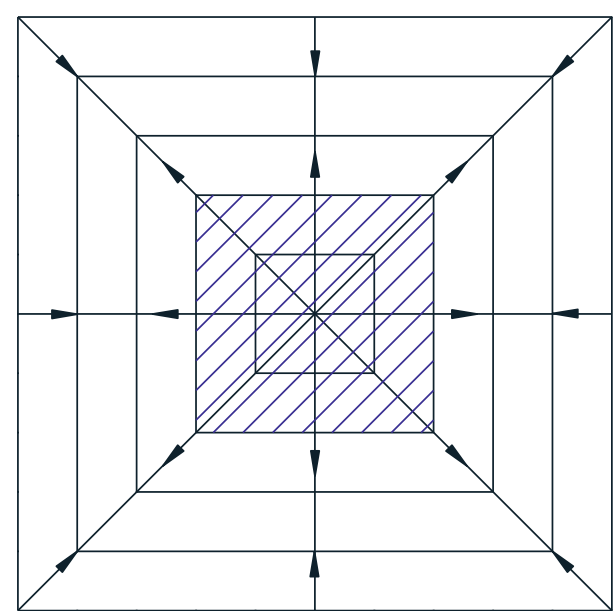

(c)

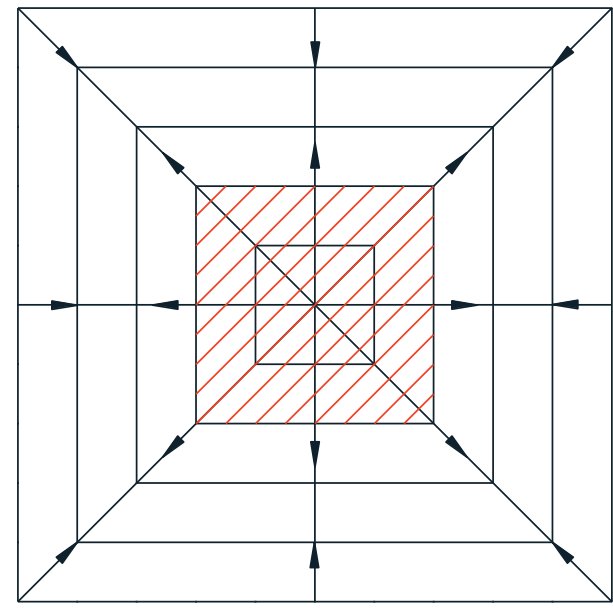

(e)

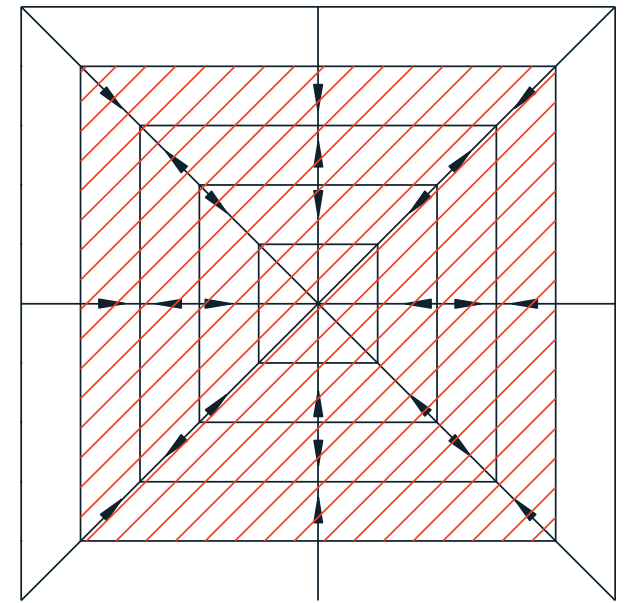

(b)

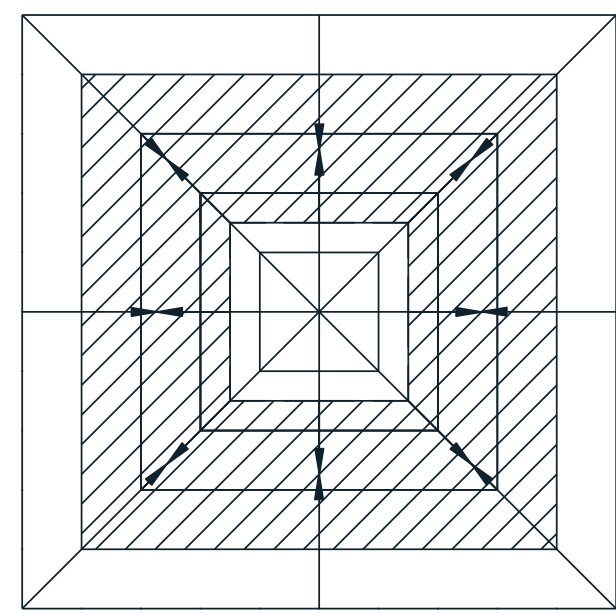

(d)

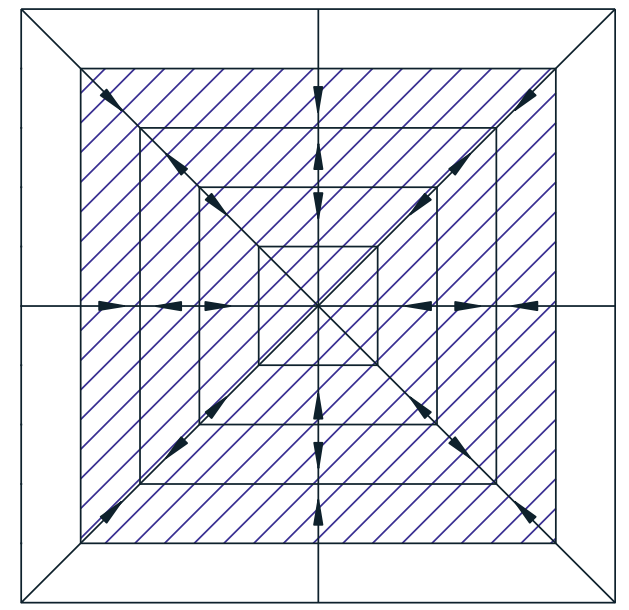

(f)

Figure 9: Developments of cross/longitudinal-section damages and severe damage areas of different freeze-thaw damage models. (a) Zgrade of $4.8 \%$ asphalt-aggregate ratio. (b) Z-grade of 5.3\% asphalt-aggregate ratio. (c) Z-grade of 5.8\% asphalt-aggregate ratio. (d) S-grade of $4.8 \%$ asphalt-aggregate ratio. (e) S-grade of 5.3\% asphalt-aggregate ratio. (f) S-grade of $5.8 \%$ asphalt-aggregate ratio.

damaged area is similar to Z-grade mixture. Therefore, the amount of asphalt should be appropriately increased to improve the antifreeze-thaw performance. In Figure 9(e), as for S-grade mixture of $5.3 \%$ asphalt-aggregate ratio, the frost-heave effect and the change in porosity cause more damage to the mixture than the coarse aggregate structure with the increase of the number of freeze-thaw cycles. Moisture damage develops from the inside to the outside. 
Therefore, the quantity of asphalt and fine aggregate is to be appropriately improved to delay the mass loss of fine aggregate and antifreeze-thaw performance. In Figure 9(f), $\mathrm{S}$-grade mixture is in an over compact state, and it is severely damaged except for the outermost layer. Therefore, appropriately reducing the quantity of asphalt and fine aggregate can improve the freeze-thaw resistance.

\section{Conclusions}

(1) Based on the splitting performance of the asphalt mixtures, the freeze-thaw damage development mechanism of the asphalt mixture was built, and the damage degree $D_{\mathrm{T} n}$ was defined. The splitting performance of the asphalt mixture decreases with the number of freeze-thaw cycles. The damage evolution equation was established based on the first order difference method, in which the freeze-thaw damage evolution was discontinuous. The progress of the freeze-thaw damage can be divided into three stages, i.e., the rapid damage stage, the stable damage stage, and the developing damage stage.

(2) For Z-grade mixture, the split freeze-thaw damage $D_{\mathrm{T} n}$ of the $5.8 \%$-asphalt-aggregate ratio mixture is $67.19 \%$ after the 18 th freeze-thaw cycle, which is $6.55 \%$ and $6.05 \%$ lower than the other two types of mixtures. For the S-grade mixture, the split freezethaw damage $D_{\mathrm{Tn}}$ of the $5.8 \%$-asphalt-aggregateratio mixture is $60.53 \%$ after the 18 th freeze-thaw cycle, which is $5.58 \%$ and $9.8 \%$ lower than the other two types of mixtures, respectively. Ordinarily, a smaller damage degree value means a preferable antifreeze-thaw property, indicating that the increasing asphalt-aggregate ratio has a significant influence on the antifreeze-thaw property of the asphalt mixture. The freeze-thaw damage evolution of $\mathrm{Z}$-grade mixtures is basically consistent with that of S-grade mixtures, but when the asphalt-aggregate ratio and the number of freeze-thaw cycles are the same, the damage degree of $\mathrm{S}$-grade mixture has a maximum reduction of $11.8 \%$ compared to the damage degree of $\mathrm{Z}$-grade mixture, which indicates that the mixture with similar skeleton dense structure has better antifreeze-thaw property. Therefore, when the asphaltaggregate ratio is $5.8 \%$ and the gradation is a skeleton dense structure, the asphalt mixture has the best freeze-thaw resistance.

(3) Based on the damage degree, a physical probability freeze-thaw damage model for the asphalt mixtures was built, the physical significance of various parameters (the shape parameter $\alpha$, the scale factor $\lambda$, and the gradient factor $\nu$ ) in the model was analyzed, and the uneven damage development processes of different types of the asphalt mixtures were analyzed. The asphalt-aggregate ratio and the gradation affect the damage development process of the asphalt mixture under the freeze-thaw cycle. The asphalt mixtures with different asphalt-aggregate ratios and gradation types can have similar freeze-thaw damage development paths.

(4) For Z-grade mixtures, when the asphalt-aggregate ratio is $4.8 \%$ or $5.3 \%$, the antifreeze-thaw performance of the asphalt mixture can be improved by improving the quantity of medium and fine aggregates. When the asphalt-aggregate ratio is $5.8 \%$, because the asphalt content is high and the aggregate is in a suspended state, the quantity of asphalt can be appropriately reduced to improve the freeze-thaw resistance of the asphalt mixture.

(5) For S-grade mixtures, the skeleton dense structure is not formed at $4.8 \%$ asphalt-aggregate ratio, and the freeze-thaw resistance of the asphalt mixture can be improved by increasing the quantity of the asphalt. In the case of $5.3 \%$ asphalt-aggregate ratio, the quantity of asphalt and fine aggregate can be improved to delay the development of freeze-thaw damage. In the case of $5.8 \%$ asphalt-aggregate ratio, the quantity of the asphalt and the fine aggregate can be appropriately reduced to improve its freeze-thaw resistance.

\section{Data Availability}

The data used to support the findings of this study are available from the first author upon request.

\section{Conflicts of Interest}

The authors declare that they have no conflicts of interest.

\section{Authors' Contributions}

Yazhen Sun, Man Deng, and Huaizhi Zhang wrote the manuscript; Lin Gao, Youlin Ye, and Zuoxin Ma performed the tests and research; and Yazhen Sun and Huaizhi Zhang checked the manuscript.

\section{Acknowledgments}

This research was performed at the Shenyang Jianzhu University and Institute of Transportation Engineering of Zhejiang University. The research was funded by the National Natural Science Fund (51478276) and Natural Science Foundation of Liaoning Province (2019-ZD-0667).

\section{References}

[1] Z. Zhang and I. Damnjanović, "Applying method of moments to model reliability of pavements infrastructure," Journal of Transportation Engineering, vol. 132, no. 5, pp. 416-424, 2006.

[2] F. Hong and J. A. Prozzi, "Estimation of pavement performance deterioration using bayesian approach," Journal of Infrastructure Systems, vol. 12, no. 2, pp. 77-86, 2006.

[3] W. Si and B. Ma, "Analysis of asphalt pavement performance under freeze-thaw cycles using reliability method," Journal of 
Jilin University (Engineering and Technology Edition), vol. 46, no. 1, pp. 126-132, 2016.

[4] S. Lamothe, D. Perraton, and H. Di Benedetto, "Contraction and expansion of partially saturated hot mix asphalt samples exposed to freeze-thaw cycles," Road Materials and Pavement Design, vol. 16, no. 2, pp. 277-299, 2014.

[5] B. Amini and S. S. Tehrani, "Simultaneous effects of salted water and water flow on asphalt concrete pavement deterioration under freeze-thaw cycles," International Journal of Pavement Engineering, vol. 15, no. 5, pp. 383-391, 2012.

[6] E. Özgan and S. Serin, "Investigation of certain engineering characteristics of asphalt concrete exposed to freeze-thaw cycles," Cold Regions Science and Technology, vol. 85, pp. 131-136, 2013.

[7] D. Feng, J. Yi, D. Wang, and L. Chen, "Impact of salt and freeze-thaw cycles on performance of asphalt mixtures in coastal frozen region of China," Cold Regions Science and Technology, vol. 62, no. 1, pp. 34-41, 2010.

[8] W. Si, B. Ma, H.-N. Wang, N. Li, and J. Hu, "Analysis of compressive characteristics of asphalt mixture under freezethaw cycles in cold plateau regions," Journal of Highway and Transportation Research and Development (English Edition), vol. 7, no. 4, pp. 17-22, 2013.

[9] D. Zhang, M. Mao, Q. Yang, W. Zhang, and P. Han, "Experimental investigation of neutralisation of concrete with fly ash as fine aggregate in freeze-thaw environment," Advances in Civil Engineering, vol. 2019, Article ID 6860293, 12 pages, 2019.

[10] Q. Zhang, Y. Bai, and J. L. I. Dai, "Influence of inorganic additives on Marshall test results of asphalt mixture," Highway, vol. 2007, no. 4, pp. 158-161, 2007.

[11] Q. Zhang, Z. Li, Z. G. Wen et al., "Research on freeze-thaw damage characteristics of asphalt mixture considering load action," Journal of Glaciology and Geocryology, vol. 39, no. 2, pp. 358-365, 2017.

[12] F. Li, "Research on meso-structure and water damage of asphalt pavement," Ph.D. thesis, Wuhan University of Technology, Wuhan, China, 2006.

[13] G. Xu, Y. H. Yu, D. G. Cai, G. Xie, X. Chen, and J. Yang, "Multi-scale damage characterization of asphalt mixture subject to freeze-thaw cycles," Construction and Building Materials, vol. 240, Article ID 117947, 2020.

[14] F. Chen and P. Qiao, "Probabilistic damage modeling and service-life prediction of concrete under freeze-thaw action," Materials and Structures, vol. 48, no. 8, pp. 2697-2711, 2014.

[15] L. L. Chen, Z. D. Qian, D. X. Chen, and Y. Wei, "Feasibility evaluation of a long-life asphalt pavement for steel bridge deck," Advances in Civil Engineering, vol. 2020, Article ID 5890945, 8 pages, 2020.

[16] L. L. Chen, G. Liu, Z. D. Qian, and X. Zhang, "Determination of allowable rutting depth based on driving safety analysis," Journal of Transportation Engineering Part B Pavements, vol. 146, no. 2, Article ID 04020023, 2020.

[17] A. X. Meng, H. N. Xu, X. L. Feng, and Y. Tan, "Feasibility of freeze-thaw damage analysis for asphalt mixtures through dynamic nondestructive testing," Construction and Building Materials, vol. 233, Article ID 117220, 2020.

[18] L. Zhang, T.-S. Li, and Y.-Q. Tan, "The potential of using impact resonance test method evaluating the anti-freeze-thaw performance of asphalt mixture," Construction and Building Materials, vol. 115, pp. 54-61, 2016.

[19] H. Y. Xu, S. Y. Dang, and D. Y. Cui, "Durability test research of asphalt mixture with rubber particles under the condition of freeze-thaw cycle," Advanced Materials Research, vol. 919-921, pp. 1096-1099, 2014.

[20] J.-R. Wu, F. Li, and Q.-Y. Ma, "Effect of polyester fiber on air voids and low-temperature crack resistance of permeable asphalt mixture," Advances in Civil Engineering, vol. 2020, Article ID 2381504, 12 pages, 2020.

[21] Y. C. Cheng, W. S. Wang, Y. F. Gong, S. Wang, S. Yang, and $\mathrm{X}$. Sun, "Comparative study on the damage characteristics of asphalt mixtures reinforced with an eco-friendly basalt fiber under freeze-thaw cycles," Materials, vol. 11, no. 12, Article ID 2488, 2018.

[22] Y. C. Cheng, D. Yu, G. J. Tan, and C. Zhu, "Low-temperature performance and damage constitutive model of eco-friendly basalt fiber-diatomite-modified asphalt mixture under freeze-thaw cycles," Materials, vol. 11, no. 11, Article ID 2148, 2018.

[23] Z. S. Li, Y. Q. Tan, S. G. Wu et al., "The effects of the freezethaw cycle on the mechanical properties of the asphalt mixture," Journal of Harbin Engineering University, vol. 35, no. 3, pp. 378-382, 2014.

[24] Y. G. Guan, W. Sun, and C. W. Miao, "One service-life prediction model for the concrete based on the reliability and damage theories I: narration and establishment of the model," Journal of the Chinese Ceramic Society, vol. 29, no. 6, pp. 530-534, 2001.

[25] Y. G. Guan, W. Sun, and C. W. Miao, "One service-life prediction model for the concrete based on the reliability and damage theories II: verification and application of the model," Journal of the Chinese Ceramic Society, vol. 29, no. 6, pp. 535-540, 2001.

[26] B. W. Lan, "Study on assessment of the residual life of the asphalt mixture after freeze-thaw," Engineering Masters thesis, Harbin Institute of Technology, Harbin, China, 2009.

[27] Z. S. Li and Y. Q. Tan, "Research on asphalt mixture freezingthawing performance," China Sciencepaper, vol. 9, no. 11, pp. 1279-1281, 2014.

[28] Y. Q. Tan, L. D. Zhao, B. W. Lan, and L. Meng, "Research on freeze-thaw damage model and life prediction of asphalt mixture," Journal of Highway and Transportation Research and Development, vol. 28, no. 6, pp. 1-7, 2011.

[29] A. Duan, Y. Tian, J.-G. Dai, and W.-L. Jin, "A stochastic damage model for evaluating the internal deterioration of concrete due to freeze-thaw action," Materials and Structures, vol. 47, no. 6, pp. 1025-1039, 2013.

[30] Y. Zhang, F. Gu, B. Birgisson, and R. L. Lytton, "Modelling cracking damage of asphalt mixtures under compressive monotonic and repeated loads using pseudo J-integral Paris' law," Road Materials and Pavement Design, vol. 19, no. 3, pp. 525-535, 2017.

[31] Y. M. Gao, L. L. Li, and Y. Q. Zhang, "Modeling crack propagation in bituminous binders under a rotational shear fatigue load using pseudo J-integral Paris' law," Transportation Research Record Journal of the Transportation Research Board, vol. 2674, no. 1, pp. 94-103, 2020.

[32] L. L. Li, Y. M. Gao, and Y. Q. Zhang, "Crack length based healing characterisation of bitumen at different levels of cracking damage," Journal of Cleaner Production, vol. 258, Article ID 120709, 2020. 